\title{
Double-Pulse Triple-Wire MIG Welding of 6082-T6 Aluminum Alloy: Process Characteristics and Joint Performances
}

\author{
Ke Yang ${ }^{1}$, Fei Wang ${ }^{2,3}$, Hongbing Liu ${ }^{2,3}$, Peng Wang ${ }^{1}$, Chuanguang Luo ${ }^{4}$, Zhishui Yu ${ }^{2,3}$, Lijun Yang ${ }^{1}$ \\ and Huan $\mathrm{Li}^{1, *}$ \\ 1 Tianjin Key Laboratory of Advanced Joining Technology, Tianjin University, Tianjin 300072, China; \\ swsyangke@tju.edu.cn (K.Y.); wangpen_g188@163.com (P.W.); yljabc@tju.edu.cn (L.Y.) \\ 2 School of Materials Engineering, Shanghai University of Engineering Science, Shanghai 201620, China; \\ wangfei@sues.edu.cn (F.W.); lhongbing@163.com (H.L.); yu_zhishui@163.com (Z.Y.) \\ 3 Shanghai Collaborative Innovation Center of Laser Advanced Manufacturing Technology, \\ Shanghai 201620, China \\ 4 Sichuan Institution of Aerospace Systems Engineering, Chengdu 610100, China; chg_luo@163.com \\ * Correspondence: lihuan@tju.edu.cn; Tel.: +86-139-2042-6800
}

check for updates

Citation: Yang, K.; Wang, F.; Liu, H.; Wang, P.; Luo, C.; Yu, Z.; Yang, L.; Li, H. Double-Pulse Triple-Wire MIG Welding of 6082-T6 Aluminum Alloy: Process Characteristics and Joint Performances. Metals 2021, 11, 1388. https://doi.org/10.3390/met11091388

Academic Editor: Elena Scutelnicu

Received: 2 August 2021

Accepted: 26 August 2021

Published: 31 August 2021

Publisher's Note: MDPI stays neutral with regard to jurisdictional claims in published maps and institutional affiliations.

Copyright: (c) 2021 by the authors. Licensee MDPI, Basel, Switzerland. This article is an open access article distributed under the terms and conditions of the Creative Commons Attribution (CC BY) license (https:// creativecommons.org/licenses/by/ $4.0 /)$.

\begin{abstract}
High-efficiency and high-quality welding has always been the focus of welding research. This article proposes a novel double-pulse, triple-wire MIG welding process for the welding of 6082-T6 aluminum alloy. The process characteristics of welding arc and droplet transfer were studied, and the performances of weld formation, morphology, hardness, and tensile strength were tested for the $1 \mathrm{~Hz}, 3 \mathrm{~Hz}$, and $5 \mathrm{~Hz}$ double-pulse welding and normal-pulse welding. It was found that in the welding process, the pulsed arc steadily alternated among three welding wires without arc interruption, and the arc length changed periodically with the double-pulse frequency. The droplets transferred with a stable one-pulse-one-drop mode. Besides, a proper double-pulse frequency, e.g., $3 \mathrm{~Hz}$ in this case, was conducive to forming good welds with regular fish-scale patterns and no pores. The tensile strength of the joint could reach $64 \%$ of the base material's tensile strength, and its fracture belonged to plastic fracture, which occurred in the HAZ. This new welding method will have great potential in aluminum alloy welding.
\end{abstract}

Keywords: double-pulse welding; triple-wire welding; 6082 aluminum alloy; welding arc; droplet transfer; joint performance

\section{Introduction}

Due to its characteristics of low density, high specific strength, good corrosion resistance, electrical conductivity, thermal conductivity, and good mechanical properties at low temperatures, aluminum alloy has been widely used in aerospace, automotive, electrical, chemical, transportation, and other industries [1,2]. The 6082 aluminum alloy, which belongs to the Al-Mg-Si series, is the main structural material used in high-speed railway $[3,4]$.

Welding is an important method for joining aluminum alloys. However, because aluminum alloys have too high thermal conductivity, too large linear expansion coefficients, and an oxide film on the surface, they are hard to weld. Welding defects, such as incomplete fusion, slag inclusion, crack, and porosity, easily appear [5].

In recent years, great progress has been made in the research of aluminum alloy welding. The main welding methods are as follows: friction stir welding (FSW) [6-8], pulsed metal inert gas (MIG) welding [9], plasma arc welding [10], electron beam welding [11], laser welding [4,12], and laser-arc hybrid welding [13]. Compared with the other welding methods, pulse MIG welding has the advantages of low cost and high efficiency, and therefore it is widely favored in production. Based on pulse MIG welding, double-pulse MIG welding has been developed by adding low-frequency modulation pulses [14]. The 
welding pool is affected by periodic stirring, which facilitates the escape of gas from the molten pool, thereby reducing the porosity of the weld [15]. Besides, a beautiful fish-scale weld can be easily obtained [16].

Improving the welding efficiency is also the focus of research. Multi-wire welding is an effective way to improve welding efficiency, because it can effectively increase heat input and the amount of wire filling [17-21]. For examples, Ruan et al. [22] proposed double-wire MIG welding and used it to weld a high-speed train car body structure (6082-T6 aluminum alloy) with the advantages of fast welding speed, high efficiency, beautiful weld formation, and small spatter. Recently, Wu et al. [23] proposed double-wire pulsed MIG welding by adding a median waveform. The AA6061 base metal was welded, and the influence of the median current on droplet transfer was investigated.

To achieve high-efficiency welding, we developed a novel triple-wire pulse MIG welding process, where three welding wires were arranged in a torch and powered by three pulsed power sources (see Section 2.2). The steels, such as Q235 [24] and Q960 [25], were successfully welded with high efficiency and quality, and the problem of arc interference was solved by alternating current pulses among the three welding wires [26].

In this study, we extend the triple-wire pulse welding process to the welding of aluminum alloy. Besides, we introduce the double-pulse characteristic to the welding process by adding low-frequency modulated pulses in order to improve weld quality. The double-pulse, triple-wire welding is expected to have the advantages of double-pulse welding and multi-wire welding. The 6082-T6 plates were successfully welded by this method, and its process characteristics and joint performances were emphatically studied.

This paper is organized as follows. In Section 2, the double-pulse, triple-wire GMAW process is introduced. In Section 3, the process characteristics of welding arc and droplet transfer and the joint performances in terms of weld formation, morphology, hardness, and tensile strength are presented and analyzed for the welding process with different double-pulse frequencies. Finally, we summarize this paper in Section 4.

\section{Materials and Methods}

\subsection{Experimental Material}

The 6082-T6 aluminum alloy plates (Zhongwang Aluminium Co., Ltd., Liaoning, China) with dimensions of $200 \mathrm{~mm} \times 100 \mathrm{~mm} \times 8 \mathrm{~mm}$ (length $\times$ width $\times$ thickness) were used as base material. The ER5356 aluminum wire (Tianjin Golden Bridge Welding Materials International Trading Co., Ltd., Tianjin, China) with a diameter of $1.2 \mathrm{~mm}$ was used as filler material. Their chemical compositions are shown in Table 1. The mechanical properties of 6082-T6 aluminum alloy are given in Table 2. Since aluminum alloy is easy to be oxidized, the workpiece needed to be polished before welding. After that, we wiped it with alcohol and immediately performed welding.

Table 1. Chemical compositions of the workpiece and wire, data from [27,28].

\begin{tabular}{cccccccccc}
\hline Aluminum Alloy & $\mathbf{M g}$ & $\mathbf{S i}$ & $\mathbf{M n}$ & $\mathbf{F e}$ & $\mathbf{C u}$ & $\mathbf{C r}$ & $\mathbf{Z n}$ & $\mathbf{T i}$ & $\mathbf{A l}$ \\
\hline 6082-T6 & 0.83 & 0.82 & 0.62 & 0.24 & 0.027 & 0.086 & 0.024 & 0.011 & Bal. \\
ER5356 & $4.5-5.5$ & 0.25 & $0.05-0.2$ & 0.4 & 0.1 & $0.05-0.20$ & 0.01 & $0.06-0.2$ & Bal. \\
\hline
\end{tabular}

Table 2. Mechanical properties of 6082-T6 aluminum alloy, data from [29].

\begin{tabular}{ccc}
\hline Tensile Strength $\sigma_{\mathbf{b}} /(\mathbf{M P a})$ & Yield Strength $\sigma_{\mathbf{s}} /(\mathbf{M P a})$ & Elongation $\varepsilon /(\%)$ \\
\hline $308-315$ & $262-274$ & $10.6-12.2$ \\
\hline
\end{tabular}

\subsection{Double-Pulse, Triple-Wire MIG Welding Process}

Figure 1 shows the experimental system of the double-pulse, triple-wire MIG welding process. It was divided into three parts: a welding system, a high-speed camera, and an electrical signal acquisition device. The welding process was performed on the welding 
system. The process characteristics of welding arc and droplet transfer were studied by the high-speed camera. The welding current and arc voltage were measured by the electrical signal acquisition device.

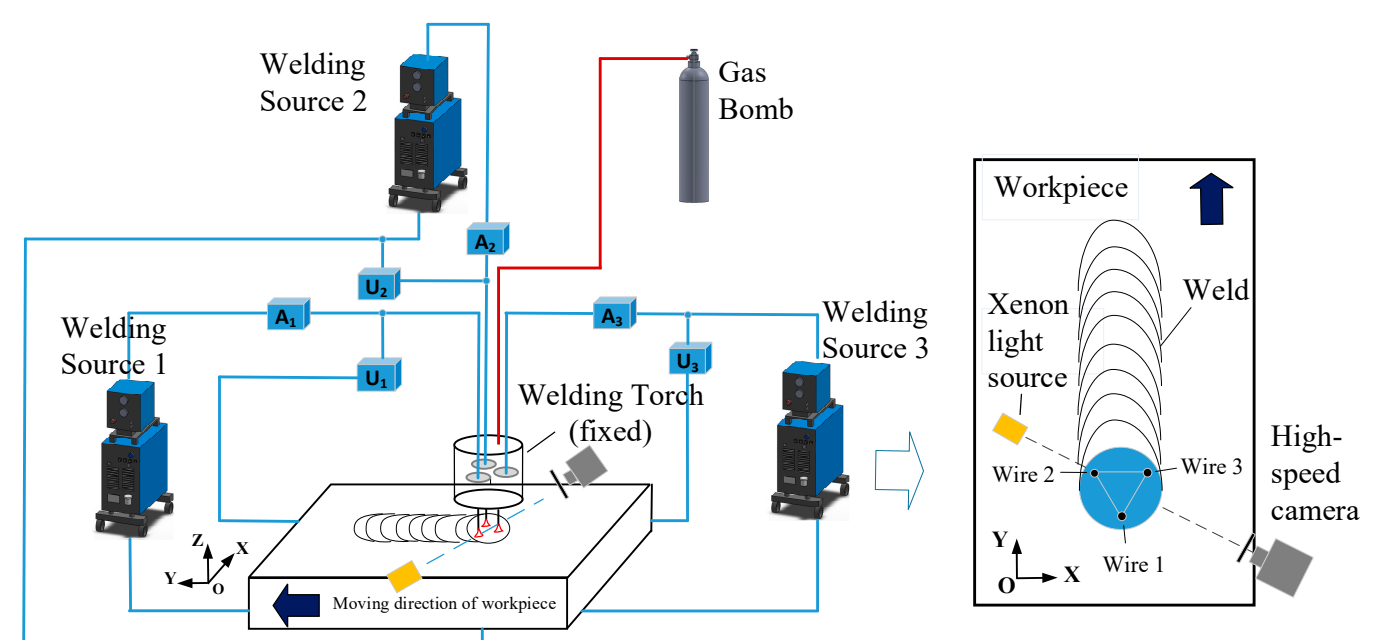

Figure 1. Schematic diagram of the experimental system.

\subsubsection{Welding System and Parameters}

As shown in Figure 1, the welding system included three MIG welding machines (AoTai PulseMIG-500, Aotai Electric Co., Ltd., Jinan, Shandong, China), a homemade welding torch, and a welding workbench. The welding wires were insulated from each other and arranged in the welding torch in the form of an equilateral triangle, and they were powered by three welding machines, respectively. A standard polarity of electrode positive was used for the MIG welding, i.e., the wires were the anode, and the workpiece was the cathode. The three welding machines had a communication function, which made a pulse arc alternately on each welding wire, as shown in Figure 2. In the pulse peak stage, the arc flashed brightly. In the pulse base stage, the arc was dim. Even due to the bright background, the arc was almost invisible, but it was not broken at this time.

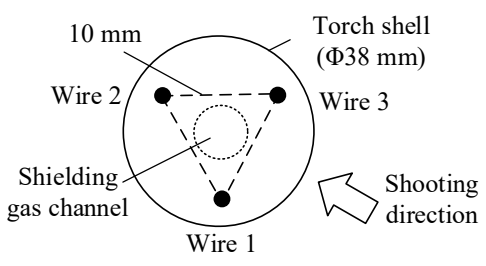

(a)
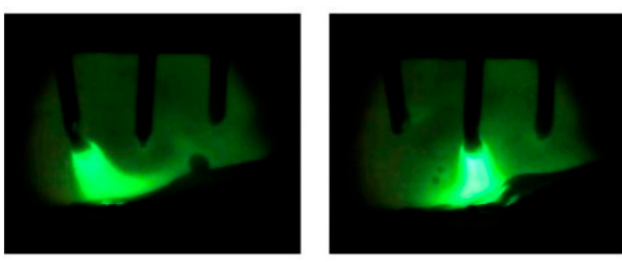

(b)

Figure 2. Alternating combustion of the pulsed arc among three wires, (a) arrangement position of welding wires, (b) welding arcs at different pulse moments.

A double-pulse current was used for each wire. To illustrate its characteristics, Figure 3 compares the electrical signals for normal-pulse mode and double-pulse mode. As shown in Figure 3, the pulse frequency $f_{\mathrm{p}}$ is the inverse of the pulse period $\Delta t$. In normal-pulse mode, the pulse frequency was almost unchanged, while it changed periodically in doublepulse mode. A double-pulse period can be divided into two stages: strong-pulse group ( $t_{1}$ stage) and weak-pulse group ( $t_{2}$ stage). The double-pulse frequency $f_{\mathrm{d}}$ is the inverse of the double-pulse period $\left(t_{1}+t_{2}\right)$. The pulse frequency in the strong-pulse group was higher than that in the weak-pulse group, and the pulse peak value and pulse base value in the strong-pulse group were also slightly higher. 


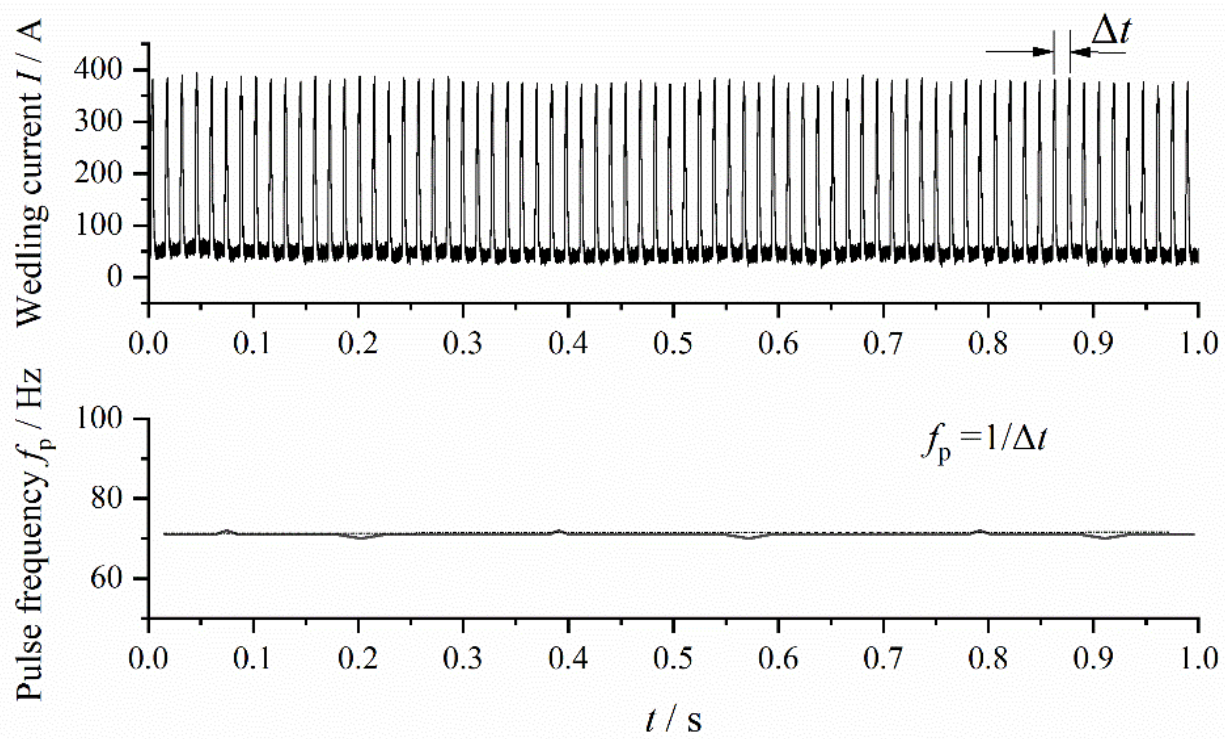

(a) Normal pulse mode

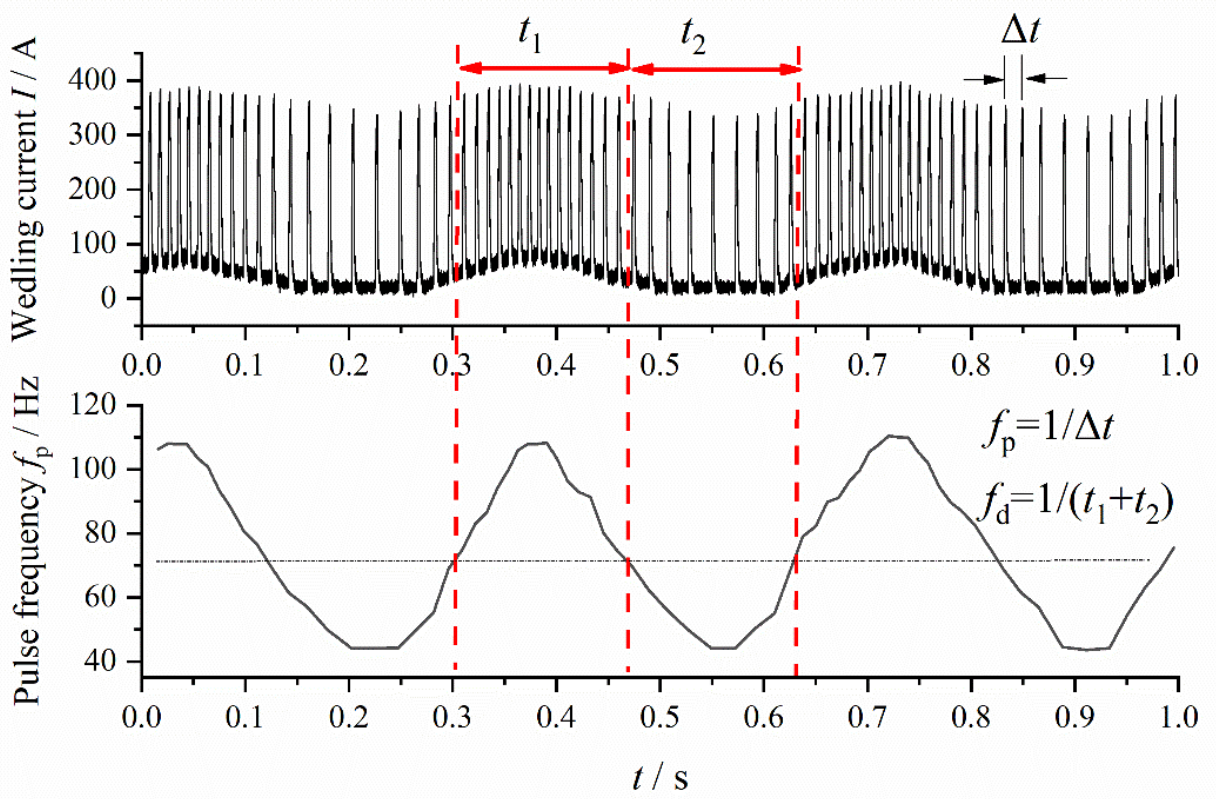

(b) Double pulse mode

Figure 3. Electrical signal characteristics of normal-pulse mode and double-pulse mode.

In this study, triple-wire welding with different double-pulse frequencies was explored, and it was compared with triple-wire welding in normal-pulse mode. The welding parameters are shown in Table 3. In the table, the preset voltage and preset current refer to the values for a single wire. The shielding gas was argon with a purity of $99.99 \%$. 
Table 3. Welding parameters for the normal-pulse and double-pulse, triple-wire MIG processes.

\begin{tabular}{cccccc}
\hline Mode & $\begin{array}{c}\text { Preset Voltage } U \\
\text { (A) }\end{array}$ & $\begin{array}{c}\text { Preset Current } I \\
\text { (A) }\end{array}$ & $\begin{array}{c}\text { Double-Pulse } \\
\text { Frequency } f_{\mathbf{d}} \\
\text { (Hz) }\end{array}$ & $\begin{array}{c}\text { Welding Speed } \\
\text { (mm/s) }\end{array}$ & $\begin{array}{c}\text { Gas Flow } \\
(\mathbf{L} / \mathbf{m i n})\end{array}$ \\
\hline Normal pulse & 18 & 110 & - & 1 & 8 \\
\hline \multirow{2}{*}{ Double pulse } & 18 & 110 & 3 & 8 & 40 \\
& 18 & 110 & 5 & 8 & 40 \\
\hline
\end{tabular}

\subsubsection{High-Speed Camera}

A MOTION PRO high-speed camera (DEL Imaging Systems, LLC., Woodsville, FL, USA) was used to shoot the welding arc and droplet transfer during the surfacing process of the flat plate. Because the arc is too bright, a $1000 \mathrm{~W}$ xenon lamp source (Microenerg Beijing Technology Co., Ltd., Beijing, China) was used to illuminate the arc to show the shadow of the droplets. This method is also known as the shadow method [30]. When shooting, the light source, welding wire, and lens should be kept on the same horizontal line. The shooting frequency was set to 2000 frames per second, and the shooting time was set to $3 \mathrm{~s}$.

\subsubsection{Electrical Signal Acquisition Device}

The electrical signal acquisition device was composed of three CHV-25P Hall voltage sensors (Beijing SENSOR Electronics Co., Ltd., Beijing, China), three CHB-1000S Hall current sensors (Beijing SENSOR Electronics Co., Ltd., Beijing, China), a NI6251 data acquisition card (National Instrument Corp., Austin, TX, USA), and LabVIEW software (National Instrument Corp., Austin, TX, USA). The signals of the welding current and arc voltage collected by the sensors were transmitted to the acquisition card through a cable. The sampling error did not exceed $5 \%$. The maximum sampling rate of a single channel was 1.0 mega points/second (MS/s). In this experiment, the sampling rate was set to $0.1 \mathrm{MS} / \mathrm{s}$ and the sampling time was set to $3 \mathrm{~s}$. In addition, the data acquisition device and the high-speed camera were triggered simultaneously with a $5 \mathrm{~V}$ high-level signal.

\subsection{Testing of Welded Joints}

To study weld formation and weld morphology, we performed surface surfacing on a flat aluminum plate by the triple-wire welding process. The weld formation was photographed with a Canon EOS 850D camera. The weld morphology was observed with an OLYPUS SZX12 stereomicroscope (Olympus Corporation, Tokyo, Japan).

To study the joint performances, we designed a joint form with a V-shaped groove (Figure 4) and performed butt welding. As shown in Figure 4, the groove angle $\alpha$ was $60^{\circ}$, the thickness of the plates $t$ was $8 \mathrm{~mm}$, the depth of the root face $c$ was $2 \mathrm{~mm}$, and the root gap $b$ was $2 \mathrm{~mm}$. Then, the hardness, tensile strength, and fracture morphology of the welded joints were tested.

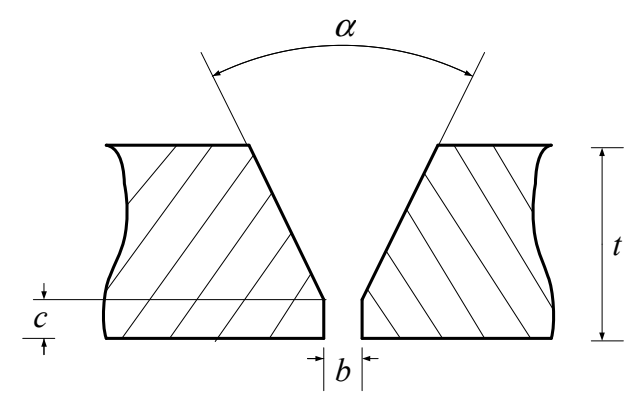

Figure 4. Groove design for butt welding samples. 
The hardness was measured with a micro-hardness tester (Aoka Industry Technology Co., Ltd., Suzhou, China) according to the ISO 9015-1:2001 standard (Destructive tests on welds in metallic materials-Hardness testing-Part 1: Hardness test on arc welded joints). The test locations, which were located at the middle depth of the plate thickness, are marked with red dots in Figure 5. Since the hardness distribution of the joint is symmetrical with the centerline of the weld, the hardness test was carried out with the center of the weld as the starting point. The interval between two adjacent points was $0.25 \mathrm{~mm}$, the load was $500 \mathrm{gf}$, and the loading time was $15 \mathrm{~s}$.

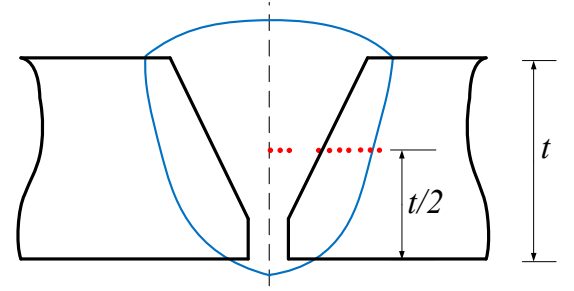

Figure 5. Schematic diagram of hardness test locations.

The tensile strength was measured with a DDL300 electronic universal testing machine (CIMACH, Changchun, Jilin, China) according to the ISO 4136:2012 standard (Destructive tests on welds in metallic materials-Transverse tensile test). The tensile specimen size is given in Figure 6. Then, the microscopic morphology of the fracture was photographed with a SU1510 scanning electron microscope (Hitachi Co., Ltd., Tokyo, Japan).

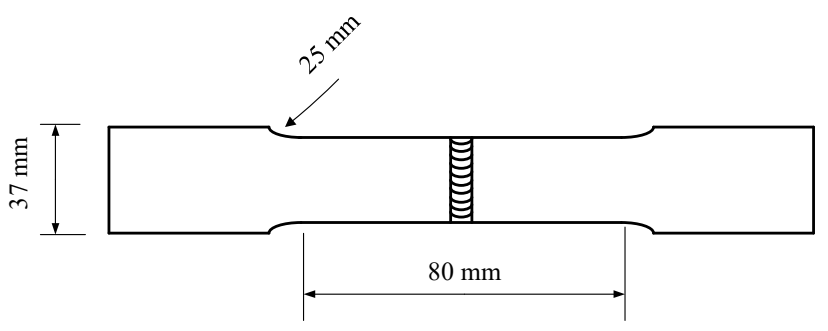

Figure 6. Schematic diagram of the tensile specimen size.

\section{Results and Discussion}

\subsection{Welding Arc and Droplet Transfer}

Welding arc and droplet transfer are important welding process characteristics, which directly determine whether the welding process is good. Through the analysis of highspeed camera and electrical signals, it was found that regardless of normal-pulse mode or double-pulse mode, the pulse arc of triple-wire welding can alternate steadily among three wires. During the welding process, there was no arc interruption, and the droplet transfer maintained a stable one-pulse-one-drop mode. The welding arc and droplet transfer during the flat surfacing process were observed. Figure 7 shows the welding arc and droplet transfer for the double-pulse, triple-wire welding process with a double-pulse frequency of $3 \mathrm{~Hz}$ as an example. 

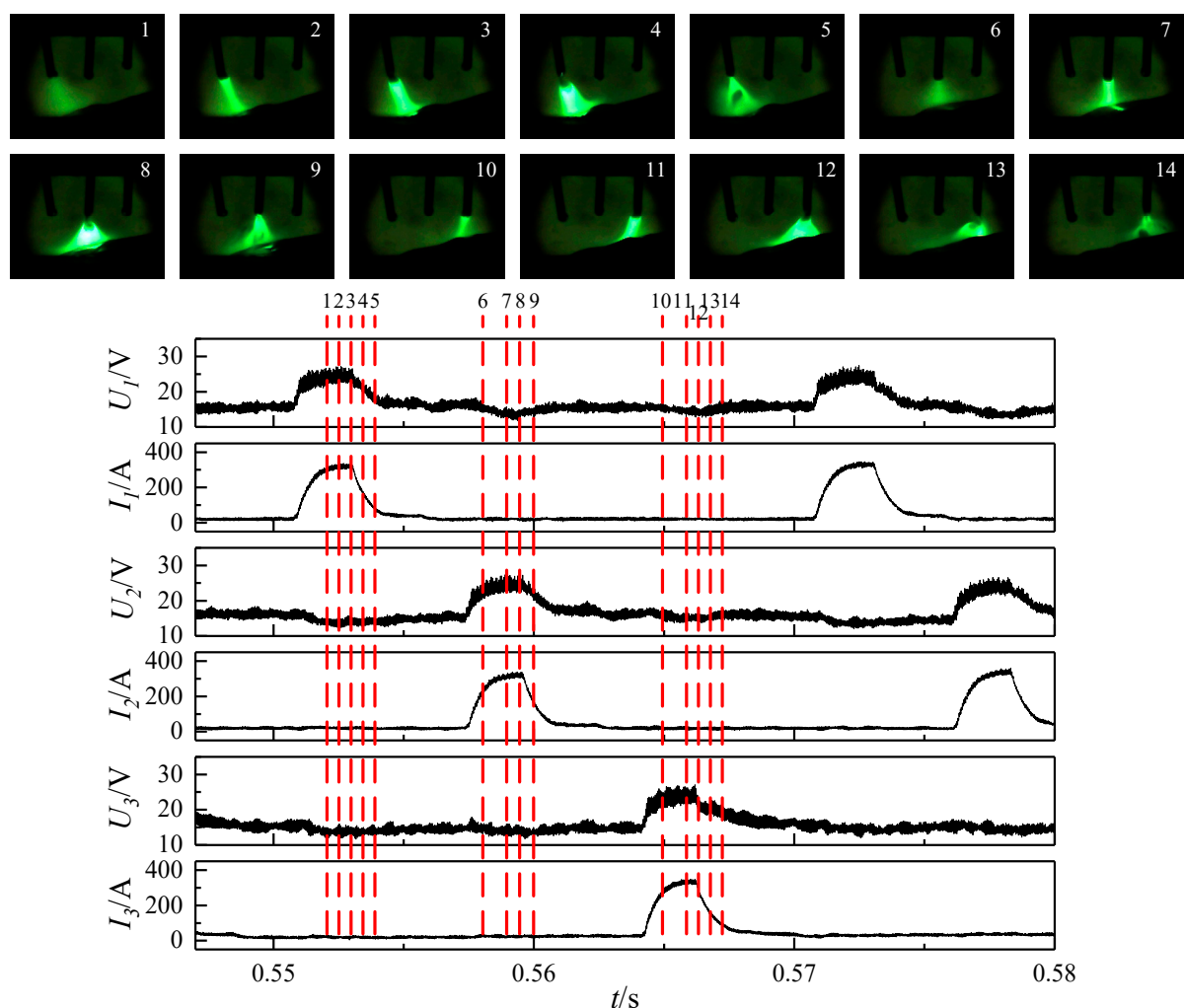

Figure 7. Welding arc and droplet transfer in the double-pulse, triple-wire welding process (doublepulse frequency $f_{\mathrm{d}}=3 \mathrm{~Hz}$ ).

The above results are mainly determined by the characteristics of the alternating pulse of the three-wire welding. The main problem of multi-wire welding is the interference between arcs. Severe arc interference may cause arc interruption, which in turn affects the droplet transfer. Our previous study [25] found that when the three arcs are alternately pulsed, the arc interference is the smallest, while when the two arcs are in the pulse stage and one arc is in the base stage, the arc interference is the largest. In this study, although a double-pulse mode was added, it still retained the characteristics of an alternating pulse for each arc. Therefore, the interference between arcs was small and the welding process was stable.

Nevertheless, the double-pulse arc still has a feature that is different from an ordinarypulse arc, that is, the arc length changes periodically. Figure 8 shows the arc lengths at the pulse peak moment during a double-pulse stage for the $3 \mathrm{~Hz}$ double-pulse frequency. The arc on wire 1 was paid special attention. When the current pulse changed from the strong-pulse group to the weak-pulse group (stage A: 0.530-0.681 s), the arc length of wire 1 gradually became longer. When the current pulse changed from the weak-pulse group to the strong-pulse group (stage B: $0.690-0.824 \mathrm{~s}$ ), the arc length gradually became shorter.

The reason for the periodic change in the arc length was that the welding wire feeds at a constant speed but melts at an unequal speed. According to arc-anode heat transfer theory, the melting rate of the welding wire is proportional to the welding current [31]. From the weak-pulse group to the strong-pulse group, the average welding current increased as the pulse frequency increased, which led to an increase in the welding wire melting rate, but the welding wire feed speed did not change, so its arc length increased. From the strong-pulse group to the weak-pulse group, the same was true. 


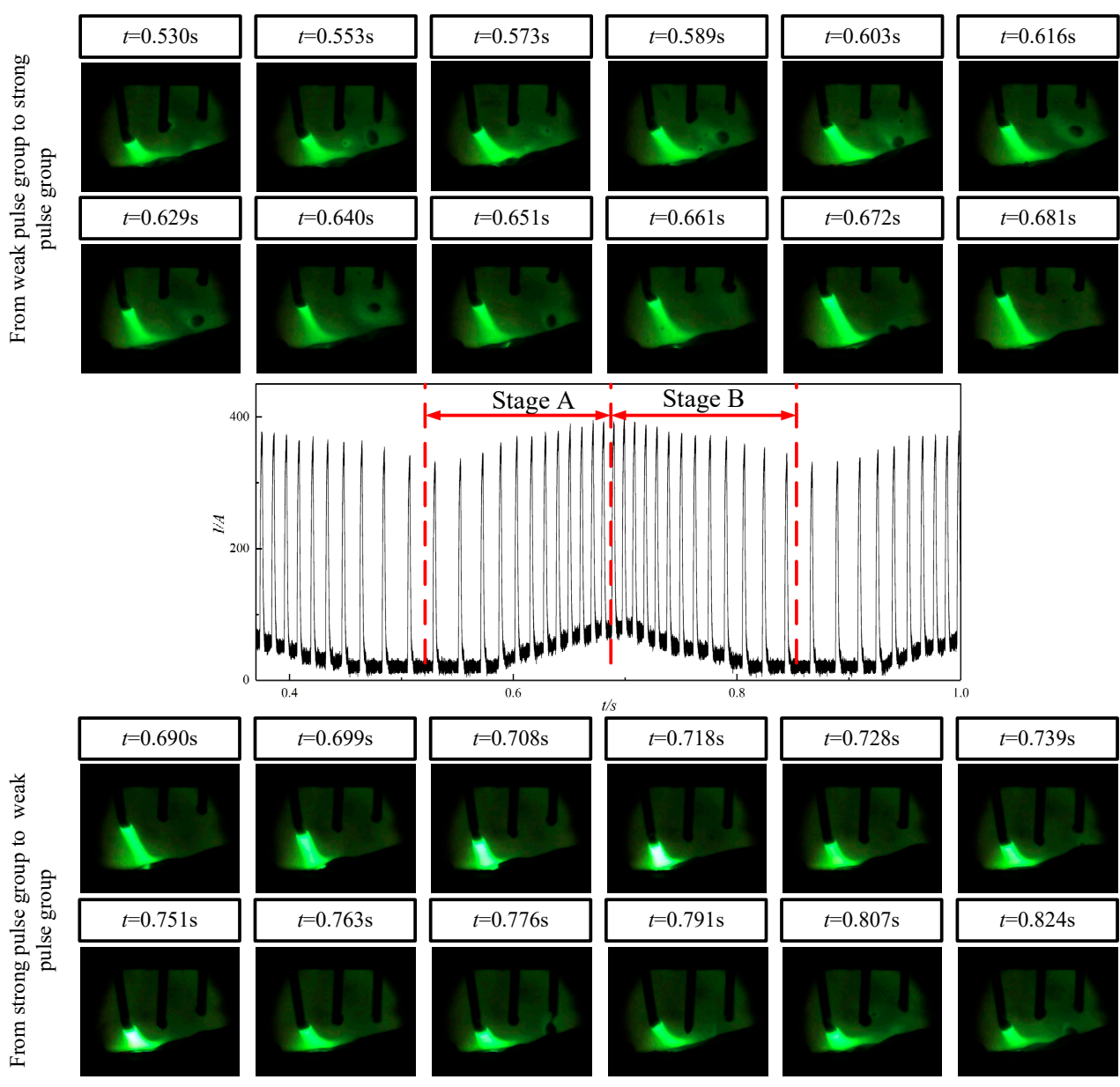

Figure 8. Arc length change during the double-pulse, triple-wire welding process (double-pulse frequency $f_{\mathrm{d}}=3 \mathrm{~Hz}$ ).

\subsection{Joint Performances}

\subsubsection{Weld Formation and Morphology}

Figure 9 shows the weld formations of the surfacing process for the three-wire welding processes with the normal pulse and the double pulses $\left(f_{\mathrm{d}}=1,3,5 \mathrm{~Hz}\right)$. It was found that the weld surface of all the welding processes was bright. Obvious fish-scale patterns were observed on the weld seams for the double-pulse welding. With the increase in the double-pulse frequency, the scale pattern gradually became denser. The formation of fish-scale patterns was related to the periodic impact of droplets on the molten pool. The droplet transfer frequency was high in the strong-pulse group, while it was low in the weak-pulse group. Therefore, the impact of droplets was periodic. On the whole, the fish-scale pattern was the most beautiful for the $3 \mathrm{~Hz}$ double-pulse frequency.

Figure 10 compares the weld morphology of the surfacing process for the normalpulse welding and the double-pulse welding $\left(f_{\mathrm{d}}=3 \mathrm{~Hz}\right)$. The weld width and weld depth of the normal-pulse welding were $9.91 \mathrm{~mm}$ and $1.69 \mathrm{~mm}$, respectively, while they were $10.55 \mathrm{~mm}$ and $2.54 \mathrm{~mm}$, respectively, for the double-pulse welding. The increase in weld width and depth for the double-pulse welding may come from stronger agitation of the molten pool, which originated from the periodic impact of droplets. The stirring effect of the molten pool is also conducive to eliminating pores. As shown in Figure 10, the pores in the double-pulse weld were significantly less than those in the normal-pulse weld. Therefore, double-pulse welding has obvious advantages over normal-pulse welding in eliminating porosity. 


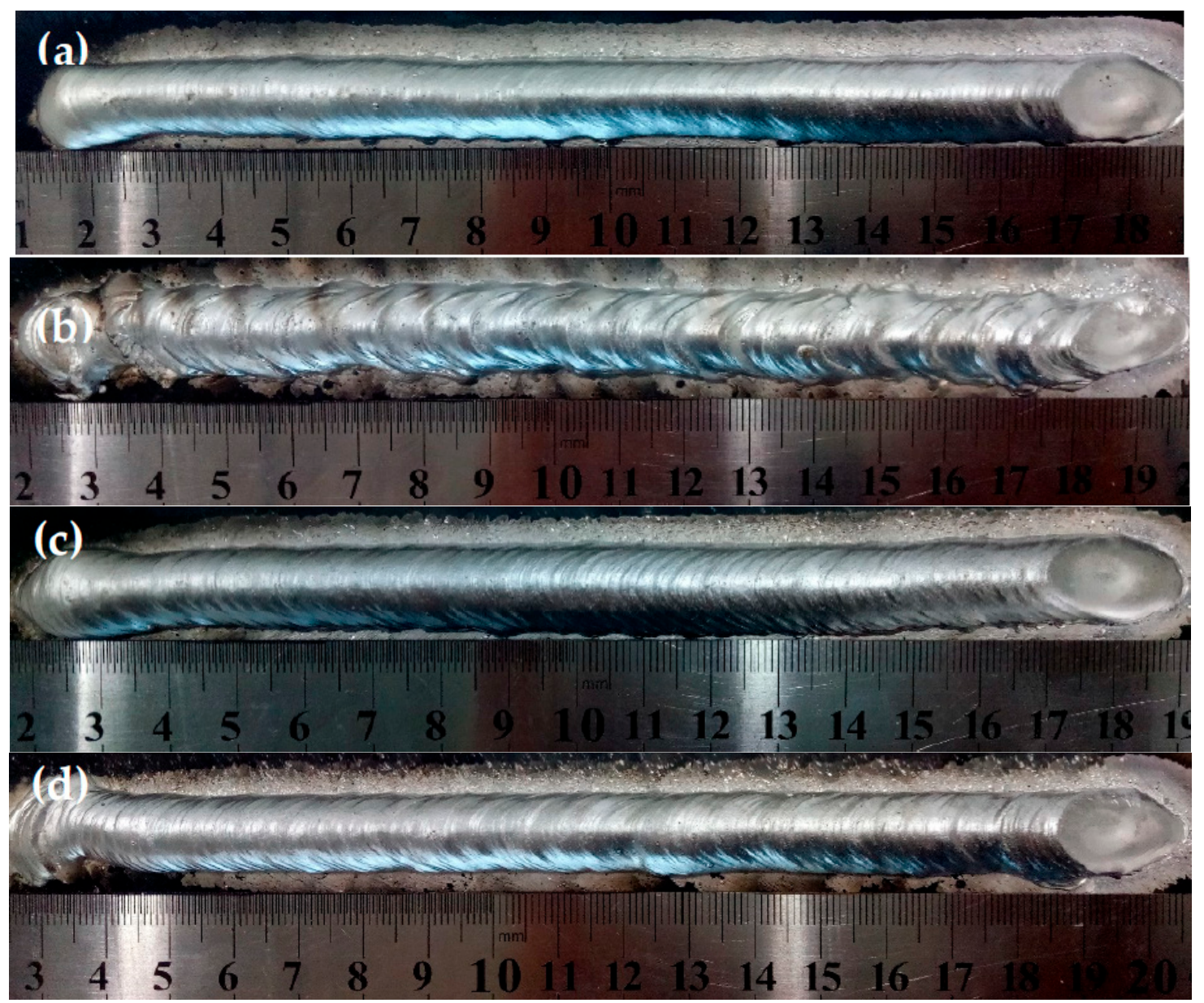

Figure 9. Weld formation for different welding models: (a) normal pulse; (b) double pulse, $1 \mathrm{~Hz}$; (c) double pulse, $3 \mathrm{~Hz}$; and (d) double pulse, $5 \mathrm{~Hz}$.
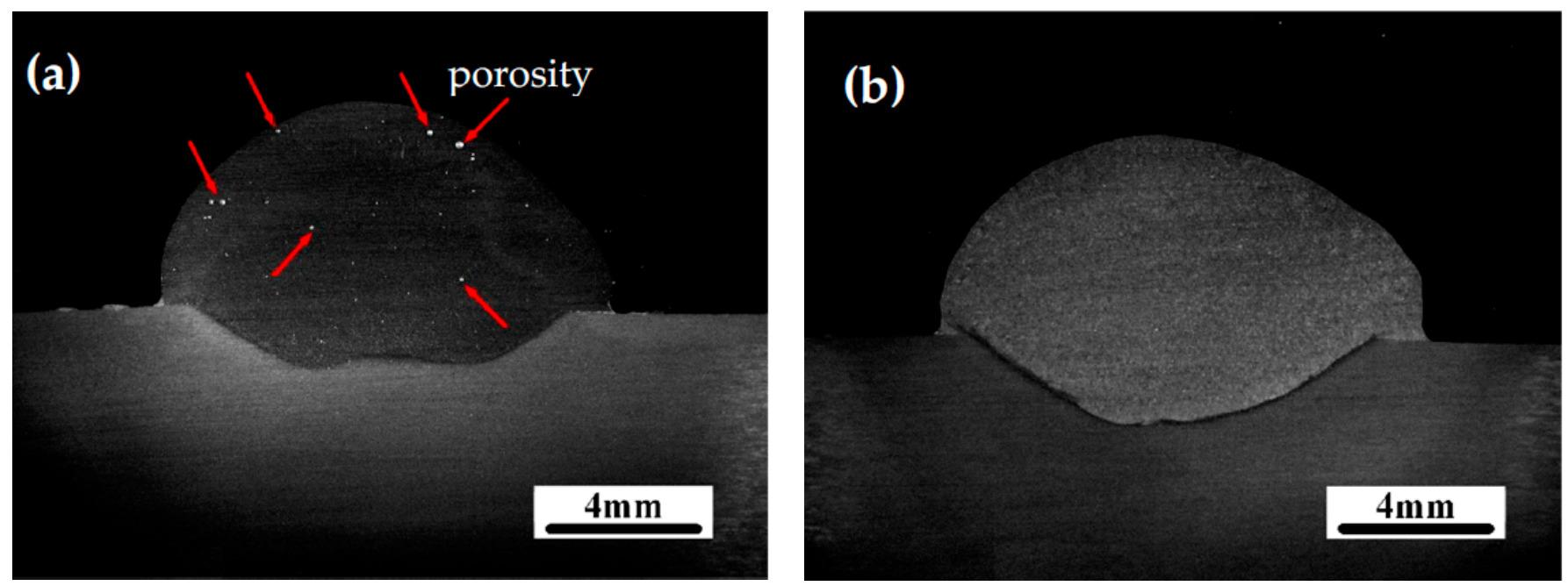

Figure 10. Comparison of weld morphology for (a) normal-pulse welding and (b) double-pulse welding $\left(f_{\mathrm{d}}=3 \mathrm{~Hz}\right)$.

\subsubsection{Weld Hardness}

Figure 11 shows the weld hardness distribution for the normal-pulse welding and the double-pulse welding $\left(f_{\mathrm{d}}=1,3,5 \mathrm{~Hz}\right)$. Their hardness distribution followed the same law: there were two troughs, which were in the center of the weld $(L \approx 0 \mathrm{~mm})$ and in the heat effect zone ( $L \approx 15 \mathrm{~mm}$ ). In other words, the welded joint has two joint-softening zones: 
weld and heat-affected zone (HAZ). This phenomenon was in line with the general law of the joint softening for the arc welding of age-strengthened aluminum alloy [5]. It was also found that the lowest hardness value appeared in the weld for the normal-pulse welding and the $5 \mathrm{~Hz}$ double-pulse welding, while it appeared in the $\mathrm{HAZ}$ for the $1 \mathrm{~Hz}$ and $3 \mathrm{~Hz}$ double-pulse welding.
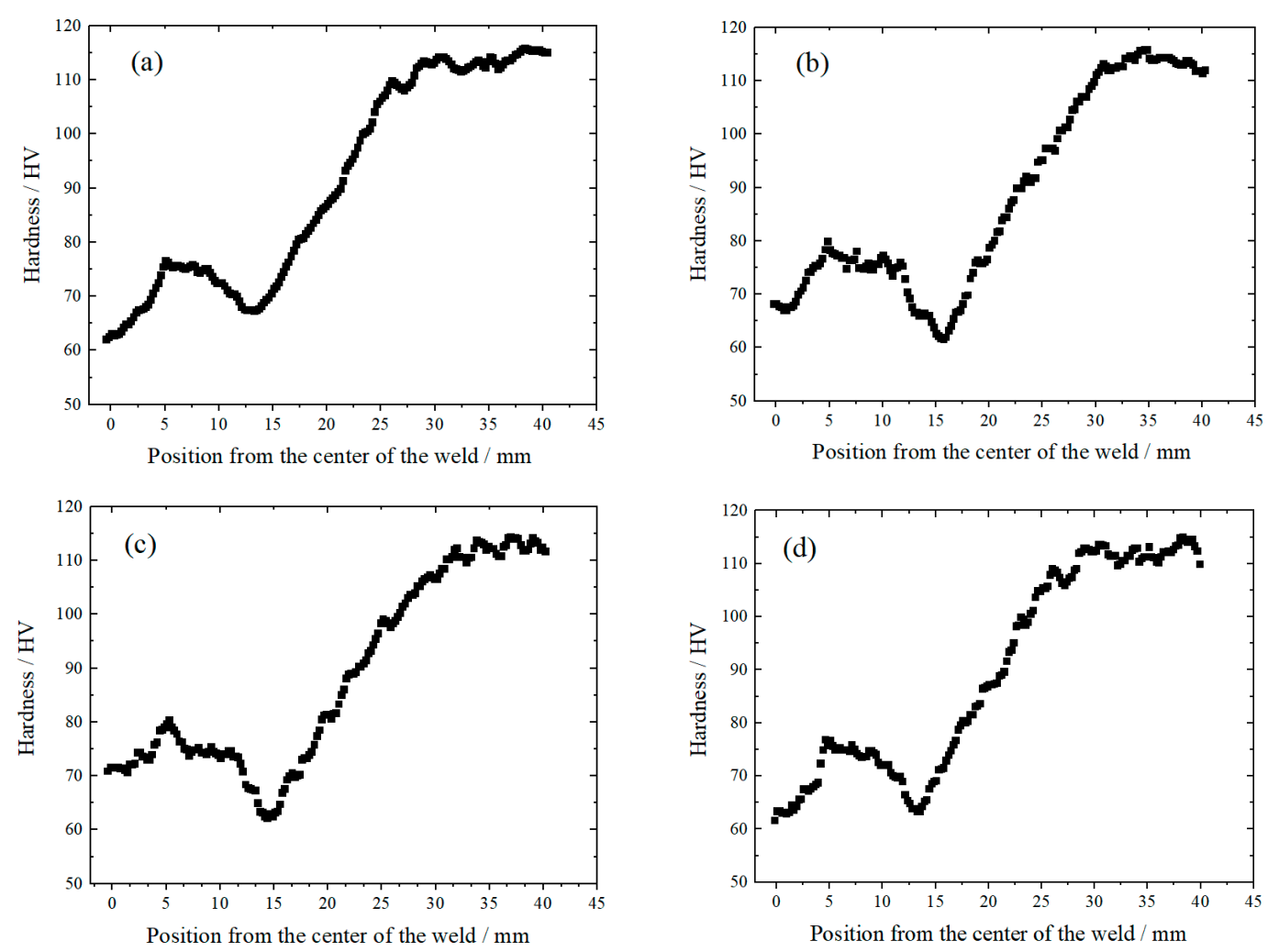

Figure 11. Hardness distribution under different welding conditions: (a) normal pulse; (b) double pulse, $1 \mathrm{~Hz}$; (c) double pulse, $3 \mathrm{~Hz}$; and (d) double pulse, $5 \mathrm{~Hz}$.

\subsubsection{Tensile Strength}

Figure 12 shows the tensile strength and fracture location of the weld joints for the normal-pulse welding and the double-pulse welding $\left(f_{\mathrm{d}}=1,3,5 \mathrm{~Hz}\right)$. The tensile strengths of the specimens were $198.57 \mathrm{MPa}, 200.92 \mathrm{MPa}$, and $189.03 \mathrm{MPa}$ for the $1 \mathrm{~Hz}, 3 \mathrm{~Hz}$, and $5 \mathrm{~Hz}$ double-pulse welding, respectively. These values were higher than the value of $185.12 \mathrm{MPa}$ for the normal-pulse welding. The samples fractured at the weld for the normal-pulse welding and the $5 \mathrm{~Hz}$ double-pulse welding, while they fractured at the HAZ for the $1 \mathrm{~Hz}$ and $3 \mathrm{~Hz}$ double-pulse welding. These fracture characteristics were consistent with the hardness distribution shown in Figure 11.

For normal-pulse welding, there are many pores in the weld, as shown in Figure 13. The existence of pores weakens the strength of the weld, causing the sample to break on the weld instead of the HAZ. For the double-pulse welding, an appropriate double-pulse frequency of $3 \mathrm{~Hz}$ can effectively reduce weld porosity and its fracture is a ductile fracture that occurs in the HAZ. Its tensile strength $(200.92 \mathrm{MPa})$ can reach $64 \%$ of the base material's tensile strength (308-315 MPa), which can meet general requirements. 


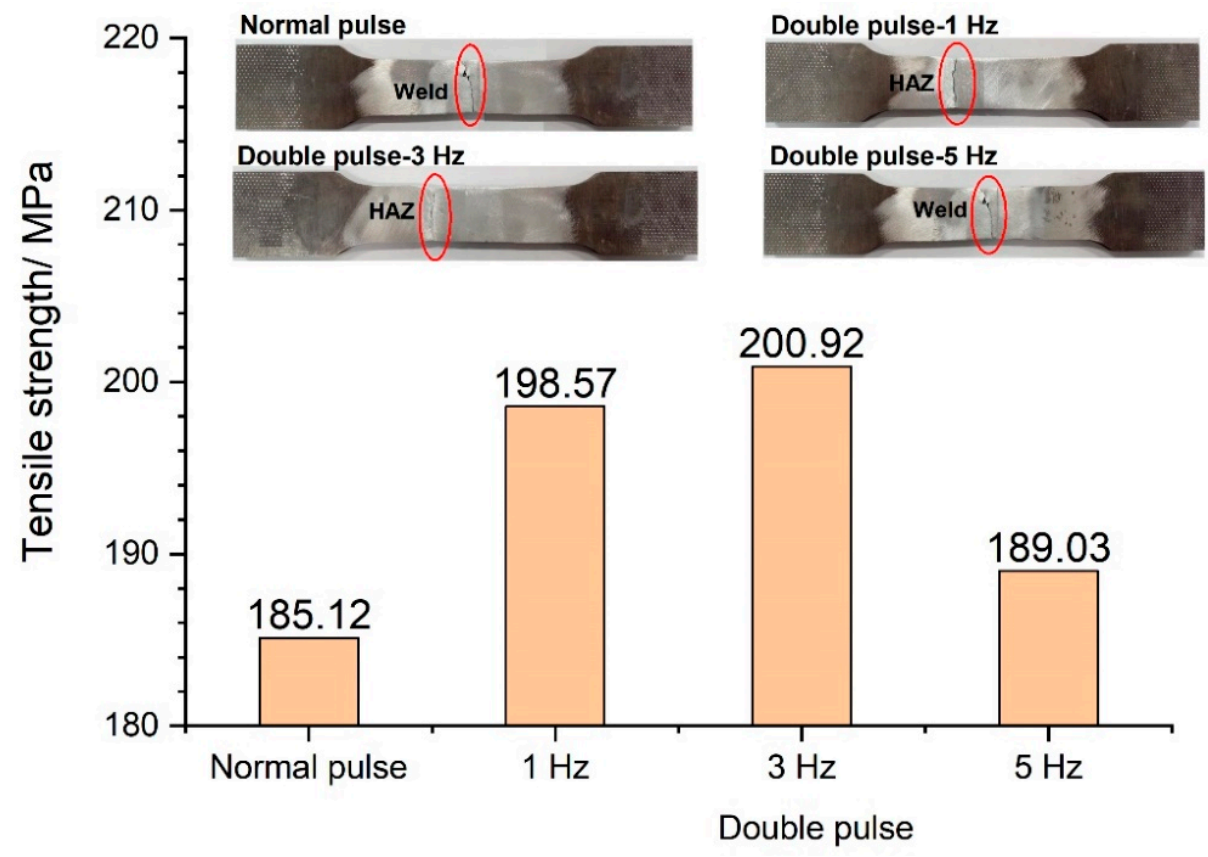

Figure 12. Tensile strength and fracture location of weld joints for the normal-pulse welding and the double-pulse welding $\left(f_{\mathrm{d}}=1,3,5 \mathrm{~Hz}\right)$.
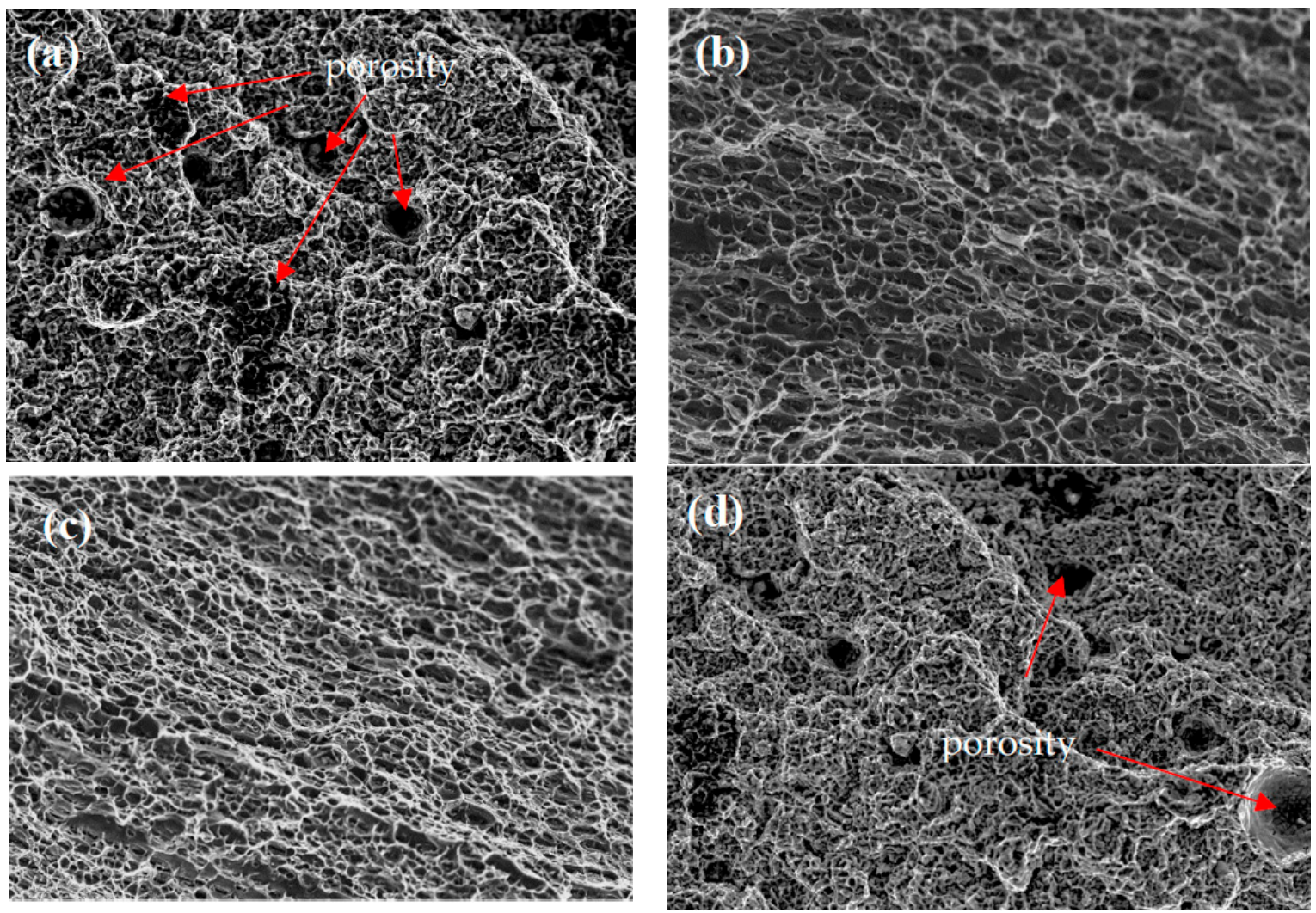

Figure 13. Fracture microscopic morphology of weld joints for (a) the normal-pulse welding and (b) $f_{\mathrm{d}}=1 \mathrm{~Hz},(\mathbf{c}) f_{\mathrm{d}}=3 \mathrm{~Hz}$, and (d) $f_{\mathrm{d}}=5 \mathrm{~Hz}$ double-pulse welding processes.

\section{Conclusions}

Compared with triple-wire MIG welding with normal-pulse mode, double-pulse, triple-wire MIG welding with a proper double-pulse frequency (e.g., $3 \mathrm{~Hz}$ in this case) can obtain good process characteristics and joint performances for the welding of 6082-T6 
aluminum alloy. The pulse arc stably alternated among three welding wires without arc interruption, and the droplets transferred with a stable one-pulse-one-drop mode. The weld seam was shaped into a beautiful fish-scale pattern, and there were few pores in the weld. During the stretching process, the fracture occurred in the HAZ, which belongs to plastic fracture. The tensile strength of the joint can reach $64 \%$ of the base material's tensile strength. Due to its overall performance, this method will have great potential in the welding of aluminum alloys. In the future, we plan to gradually use it in actual production.

Author Contributions: Conceptualization, K.Y. and H.L. (Huan Li); methodology, K.Y., P.W. and F.W.; software, F.W. and H.L. (Hongbing Liu); validation, K.Y., H.L. (Hongbing Liu) and F.W.; formal analysis, K.Y. and H.L. (Huan Li); investigation, K.Y. and C.L.; resources, H.L. (Huan Li), L.Y. and F.W.; data curation, K.Y. and Z.Y.; writing-original draft preparation, K.Y. and F.W.; writing-review and editing, F.W.; visualiza-tion, K.Y. and F.W.; supervision, H.L. (Huan Li); project administration, K.Y.; funding acquisition, H.L. (Huan Li) and F.W. All authors have read and agreed to the published version of the manuscript.

Funding: This research was funded by the National Natural Science Foundation of China (grant nos. 51675375 and 52005320).

Institutional Review Board Statement: Not applicable.

Informed Consent Statement: Not applicable.

Data Availability Statement: Not applicable.

Conflicts of Interest: The authors declare no conflict of interest.

\section{References}

1. Cooke, K.O. Aluminium Alloys and Composites; InTech Open: Rijeka, Croatia, 2020. [CrossRef]

2. Dashwood, R.J.; Grimes, R. Structural Materials: Aluminum and Its Alloys-Properties. In Encyclopedia of Aerospace Engineering; Mueller, E., Ed.; John Wiley \& Sons, Ltd.: New York, NY, USA, 2010. [CrossRef]

3. Verma, R.P.; Lila, M.K. A short review on aluminium alloys and welding in structural applications. Mater. Today Proc. 2021. [CrossRef]

4. Liu, C.; Wenhao, H.U.; Gao, M. Research on laser welding technology method of 6082 aluminum alloy for high speed railway vehicles. Dual Use Technol. Prod. 2013, 1, 91-94. [CrossRef]

5. Mathers, G. The Welding of Aluminium and Its Alloys; Woodhead Publishing Ltd.; CRC Press LLC: New York, NY, USA, 2012.

6. Svp, A.; Bvrrk, B.; Vvsr, C. Acoustic analysis in friction stir welding of 6082-T6 aluminium alloy plates. In Proceedings of the 9th International Conference of Materials Processing and Characterization, Hyderabad, India, 8-10 March 2019; pp. $2413-2422$.

7. Adamowski, J.; Gambaro, C.; Lertora, E.; Ponte, M.; Szkodo, M. Analysis of FSW welds made of aluminium alloy AW6082-T6. Arch. Mater. Sci. Eng. 2007, 28, 453-460.

8. Gürel, Ç.; Mistikoglu, S. Recent developments in friction stir welding of Al-alloys. J. Mater. Eng. Perform. 2014, 23, 1936-1953. [CrossRef]

9. Hongji, X.U.; Tang, H.; Liu, Z.; Xie, M.; Jiao, J. Microstructure and mechanical properties of 6082 aluminum alloy joints welded by MIG. Hot Work. Technol. 2010, 39, 131-133. [CrossRef]

10. Xu, B.; Chen, S.; Tashiro, S.; Jiang, F.; Tanaka, M. Physical mechanism of material flow in variable polarity plasma arc keyhole welding revealed by in situ X-ray imaging. Phys. Fluids 2021, 33, 017121. [CrossRef]

11. Wu, Q.S.; Feng, J.C.; He, J.S. Determination of characteristic parameters of weld penetration in electron beam welding of aluminum alloy. Trans. China Weld. Inst. 2006, 27, 15-18. [CrossRef]

12. Sánchez-Amaya, J.; Delgado, T.; González-Rovira, L.; Botana, F.J. Laser welding of aluminium alloys 5083 and 6082 under conduction regime. Appl. Surf. Sci. 2009, 255, 9512-9521. [CrossRef]

13. Faraji, A.H.; Goodarzi, M.; Seyedein, S.H.; Maletta, C. Effects of welding parameters on weld pool characteristics and shape in hybrid laser-TIG welding of AA6082 aluminum alloy: Numerical and experimental studies. Weld World 2016, 60, 137-151. [CrossRef]

14. Zhang, Z.D.; Kong, X.Y. Study on DC Double Pulse MIG Welding of Automobile Aluminum Alloy. In Advanced Materials Research; Trans Tech Publications Ltd.: Stafa-Zurich, Switzerland, 2011; Volume 295-297, pp. 1933-1937. [CrossRef]

15. Silva, C.L.M.; Scotti, A. The influence of double pulse on porosity formation in aluminum GMAW. J. Mater. Process. Technol. 2006, 171, 366-372. [CrossRef]

16. Yao, P.; Xue, J.; Meng, W.; Zhu, S. Influence of processing parameters on weld forming in double-pulse MIG welding of aluminum alloy. Trans. China Weld. Inst. 2009, 30, 69-72. [CrossRef]

17. Huang, L.; Hua, X.; Wu, D.; Jiang, Z.; Li, F.; Wang, H.; Shi, S. Microstructural characterization of 5083 aluminum alloy thick plates welded with GMAW and twin wire GMAW processes. Int. J. Adv. Manuf. Technol. 2017, 93, 1809-1817. [CrossRef] 
18. Moinuddin, S.Q.; Sharma, A. Arc stability and its impact on weld properties and microstructure in anti-phase synchronised synergic-pulsed twin-wire gas metal arc welding. Mater. Des. 2015, 67, 293-302. [CrossRef]

19. Liu, L.M.; Hu, C.H.; Yu, S.B.; Song, G. A triple-wire indirect arc welding method with high melting efficiency of base metal. J. Manuf. Process. 2019, 44, 252-260. [CrossRef]

20. Liu, L.M.; Song, G.; Fang, D.S. Experimental investigation of wire arrangements for narrow-gap triple-wire gas indirect arc welding. Mater. Manuf. Process. 2016, 31, 2136-2142. [CrossRef]

21. Ueyama, T.; Ohnawa, T.; Tanaka, M.; Nakata, K. Occurrence of arc interaction in tandem pulsed gas metal arc welding. Sci. Technol. Weld. Join. 2013, 12, 523-529. [CrossRef]

22. Ruan, Y.; Qiu, X.M.; Gong, W.B.; Sun, D.Q.; Li, Y.P. Mechanical properties and microstructures of $6082-\mathrm{T} 6$ joint welded by twin wire metal inert gas arc welding with the $\mathrm{SiO}_{2}$ flux. Mater. Des. 2012, 35, 20-24. [CrossRef]

23. Wu, K.; Zhan, J.; Cao, X.; Zeng, M.; Ding, N. Metal transfer of aluminum alloy double-wire pulsed GMAW with a median waveform. J. Mater. Process. Technol. 2020, 286, 116761. [CrossRef]

24. Liu, Y. The Arc Behavior and Characteristics in Triple-Wire Gas Metal Arc Welding Process. Master's Thesis, Tianjin University, Tianjin, China, 2015.

25. Yang, K.; Wang, F.; Duan, D.; Zhang, T.L.; Luo, C.G.; Cressault, Y.; Yu, Z.S.; Yang, L.J.; Li, H. Experimental investigation of integrated circular triple-wire pulse GMAW of Q960E high-strength steel for construction machinery. Materials 2021, 14, 375. [CrossRef]

26. Xiang, T.; Li, H.; Gao, Y.; Zhao, S.Y.; Lou, L.Y.; Wang, H. Effects of pulse phase difference on metal transfer process and weld formation in the integrated circular triple-electrode GMAW. Int. J. Adv. Manuf. Technol. 2019, 102, 857-866. [CrossRef]

27. Standardization Administration of China. National Standard of the People's Republic of China GB/T 3190-2020: Chemical Composition of Wrought Aluminium and Aluminium Alloys; Standardization Administration of China: Beijing, China, 2020.

28. Tianjin Golden Bridge Welding Materials International Trading Co., Ltd., Product Center. Available online: https://www. tjgoldenbridge.com/products/product/ulist?Types=35\&Industrys (accessed on 2 August 2021).

29. Standardization Administration of China. National Standard of the People's Republic of China GB/T 3880.2-2012: Wrought Aluminium and Aluminium Alloy Plates, Sheets and Strips for General Engineering-Part 2: Mechanical Properties; Standardization Administration of China: Beijing, China, 2012.

30. Siewert, E.; Schein, J.; Forster, G. Determination of enthalpy, temperature, surface tension and geometry of the material transfer in PGMAW for the system argon-iron. J. Phys. D Appl. Phys. 2013, 46, 224008. [CrossRef]

31. Lancaster, J.F. The Physics of Welding; Pergamon Press: Oxford, UK, 1986. 